\title{
Racial disparities in treatment patterns and clinical outcomes in patients with HER2-positive metastatic breast cancer
}

\author{
Hope S. Rugo • Adam M. Brufsky • Marianne Ulcickas Yood • \\ Debu Tripathy $\cdot$ Peter A. Kaufman · Musa Mayer • \\ Bongin Yoo $\cdot$ Oyewale O. Abidoye $\cdot$ Denise A. Yardley
}

Received: 30 August 2013/ Accepted: 6 September 2013/Published online: 24 September 2013

(C) The Author(s) 2013. This article is published with open access at Springerlink.com

\begin{abstract}
Data characterizing demographics, treatment patterns, and clinical outcomes in black patients with human epidermal growth factor receptor 2 (HER2)-positive metastatic breast cancer (MBC) are limited. registHER is a large, observational cohort study of patients $(n=1,001)$ with HER2-positive MBC diagnosed $\leq 6$ months of enrollment and followed until death, disenrollment, or June 2009 (median follow-up of 27 months). Demographics, treatment patterns, and clinical outcomes were described for black $(n=126)$ and white patients $(n=793)$. Progression-free survival (PFS) following firstline therapy and overall survival (OS) were examined. Multivariate analyses adjusted for baseline and treatment factors. Black patients were more likely than white patients to be obese (body mass index $\geq 30$ ), to have diabetes, and to have a history of cardiovascular disease; they were also less likely to have estrogen receptor or progesterone
\end{abstract}

\footnotetext{
H. S. Rugo ( $\square)$

University of California San Francisco Helen Diller Family Comprehensive Cancer Center, 1600 Divisadero Street, Box 1710, San Francisco, CA 94143-1710, USA

e-mail: hrugo@medicine.ucsf.edu

A. M. Brufsky

University of Pittsburgh Cancer Center, Pittsburgh, PA, USA

M. U. Yood

EpiSource, LLC, Boston, MA, USA

M. U. Yood

School of Public Health, Boston University School of Medicine,

Boston, MA, USA

D. Tripathy

University of Southern California/Norris Comprehensive Cancer

Center, Los Angeles, CA, USA
}

receptor positive disease. In patients treated with trastuzumab, the incidence of cardiac safety events (grade $\geq 3$ ) was higher in black patients $(10.9 \%)$ than in white patients $(7.9 \%)$. Unadjusted median OS and PFS (months) were significantly lower in black patients than in white patients (OS: black: 27.1, $95 \%$ confidence interval [CI] 21.3-32.1; white: $37.3,95 \%$ CI 34.6-41.1; PFS: black: $7.0,95 \%$ CI 5.7-8.2; white: 10.2, $95 \%$ CI 9.3-11.2). The adjusted OS hazard ratio (HR) for black patients compared with white patients was 1.29 (95\% CI 1.00-1.65); adjusted PFS HR was 1.29 (95\% CI 1.05-1.59). This real-world evaluation of a large cohort of patients with HER2-positive MBC shows poorer prognostic factors and independently worse clinical outcomes in black versus white patients. Further research is needed to identify potential biologic differences that could have predictive impact for black patients or that could explain these differences. 
Keywords Racial disparities - HER2-positive . Metastatic breast cancer - registHER - Observational study $\cdot$ Treatment patterns

\section{Introduction}

Previous literature has shown that, while the incidence of breast cancer in black women is lower than in white women, black women are more likely to die as a result of the disease [1-5], are diagnosed at an earlier age, have a higher grade at diagnosis [3, 4, 6], and have a greater risk of recurrence [4]. One factor associated with this racial disparity is being diagnosed at a later stage $[1,3,7]$, which may be contributed to by socioeconomic factors and access to care [3,7]. Reproductive variables associated with breast cancer outcome have been shown to differ between black and white women, including menopausal status, use of contraception, breast feeding behaviors [7, 8], and body mass index (BMI) [4, 7, 8]. However, even after controlling for such factors, disparities in health outcomes are still apparent, with several studies revealing potential underlying biologic differences between black and white breast cancer patients [2, 7]. In particular, a greater incidence of triple-negative breast cancer (TNBC), i.e., estrogen receptor (ER), progesterone receptor (PR), and human epidermal growth factor receptor 2 (HER2) negative or basal-like breast cancer, has been demonstrated in black women [2, 3], even when controlling for age and BMI [4]. Though data are limited, several inherited genetic factors may contribute to this biologic association; Olopade and colleagues have associated specific germline BRCAl mutations with high-risk African American kindreds [9].

About $20-25 \%$ of breast cancers have overexpression of HER2 [10,11] which is both prognostic and predictive of treatment benefit. Overexpression is associated with a higher risk of and a shorter time to relapse, as well as poorer prognosis, worse survival, and a higher likelihood of response to both specific chemotherapy regimens and biologic therapy targeted to HER2 [2, 10, 12]. Data characterizing HER2 positive metastatic breast cancer (MBC) in black patients are limited. The objective of this analysis was to examine demographics, treatment patterns, and clinical outcomes in black and white patients with HER2positive MBC in the registHER observational cohort.

\section{Methods}

registHER study design

The registHER study (NCT00105456; clinicaltrials.gov) is a multicenter, prospective, observational, US-based cohort study of patients with newly diagnosed HER2-positive
MBC $(N=1,023)$. Patients were diagnosed within 6 months of enrollment and were recruited from community and academic settings between December 2003 and February 2006. Study design and recruitment details are described elsewhere [13]. The objectives of registHER were to describe the natural history of disease and treatment patterns for patients with HER2-positive MBC and to explore associations between specific therapies and patient outcomes. Patients received care according to their physicians' standard practice, without study-specified evaluations. Prior or planned treatment with trastuzumab, or any specific HER2-targeted therapy, was not a requirement for enrollment. All patients signed an informed consent and authorized the disclosure of their health information. There were no exclusion criteria; however, patients who did not provide informed consent and did not authorize the disclosure of health information were excluded.

Patient information was recorded at enrollment and updated every 3 months. Information collected included treatment history, sites of progressive disease, tumor response, survival, cardiac safety (grades 3/4/5), and adverse events potentially related to the administration of trastuzumab. First-line treatment patterns are based on treatment received prior to first disease progression and may have been given sequentially or concurrently. History of metabolic disorders, cardiovascular disease (CVD), and data on cardiac safety were collected using predefined checkboxes. Cardiac safety events were defined based on the Common Terminology Criteria for Adverse Events, version 3.0, and selected based on physician subjective opinion [14]. The schedule for tumor assessment and time of tumor progression was determined by treating physicians per their standards of care.

\section{Statistical analysis}

Of the 1,023 patients in the registHER cohort, $22 \mathrm{did}$ not receive any treatment during the study and were excluded from the analysis. Due to small numbers, Hispanic patients $(n=56)$, Asian/Pacific Islander patients $(n=18)$, and patients classified as "other" races $(n=8)$ were also excluded. Ultimately, 126 black patients and 793 white patients were included in this study for which demographics, treatment patterns, and clinical outcomes were described $(n=919)$.

Progression-free survival (PFS) and overall survival (OS) from time of diagnosis of MBC were analyzed using the Kaplan-Meier method. Patients without a record of disease progression or death were censored at the last followup date or at the data lock date (June 15, 2009), whichever occurred earlier. Multivariate Cox regression models were used to generate hazard ratios (HRs) and $95 \%$ confidence intervals (CIs) to assess the effect of race 
Table 1 Baseline demographic and clinical characteristics of black and white patients at diagnosis of $\mathrm{MBC}$

\begin{tabular}{|c|c|c|}
\hline Characteristic & $\begin{array}{l}\text { Black } \\
\text { patients } \\
(n=126)\end{array}$ & $\begin{array}{l}\text { White } \\
\text { patients } \\
(n=793)\end{array}$ \\
\hline Median follow-up, months & 21.0 & 28.4 \\
\hline Median age, years (min-max) & $50(20-90)$ & $54(22-92)$ \\
\hline \multicolumn{3}{|l|}{ Sex, $n(\%)$} \\
\hline Female & $125(99.2)$ & $784(98.9)$ \\
\hline \multicolumn{3}{|l|}{ BMI, $\mathrm{kg} / \mathrm{m}^{2}$} \\
\hline$<30$ & $62(49.2)$ & $536(67.6)$ \\
\hline$\geq 30$ & $64(50.8)$ & $257(32.4)$ \\
\hline History of diabetes, $n(\%)$ & $17(13.5)$ & $51(6.4)$ \\
\hline $\begin{array}{l}\text { History of underlying CVD (any), }{ }^{\mathrm{a}} \\
n(\%)\end{array}$ & $38(30.2)$ & $125(15.8)$ \\
\hline Arrhythmia & $5(4.0)$ & $16(2.0)$ \\
\hline Congestive heart failure & $4(3.2)$ & $10(1.3)$ \\
\hline Hypertension with complications & $14(11.1)$ & $33(4.2)$ \\
\hline Angina & $1(0.8)$ & $2(0.3)$ \\
\hline Myocardial infarction & $3(2.4)$ & $16(2.0)$ \\
\hline Peripheral vascular disease & $2(1.6)$ & $10(1.3)$ \\
\hline Other underlying cardiac disease & $26(20.6)$ & $65(8.2)$ \\
\hline \multicolumn{3}{|c|}{ Site of metastatic disease at diagnosis, $n(\%)$} \\
\hline Any CNS & $11(8.7)$ & $57(7.2)$ \\
\hline Bone only or bone plus breast & $19(15.1)$ & $114(14.4)$ \\
\hline Visceral & $79(62.7)$ & $487(61.4)$ \\
\hline Node/local & $17(13.5)$ & $133(16.8)$ \\
\hline Other sites & $0(0.0)$ & $2(0.3)$ \\
\hline \multicolumn{3}{|c|}{ ECOG performance status at diagnosis, $n(\%)$} \\
\hline $0-1$ & $54(42.9)$ & $366(46.2)$ \\
\hline $2+$ & $12(9.5)$ & $43(5.4)$ \\
\hline Unknown/missing & $60(47.6)$ & $384(48.4)$ \\
\hline \multicolumn{3}{|l|}{ ER/PR status, $n(\%)$} \\
\hline ER-positive or PR-positive & $53(42.1)$ & $434(54.7)$ \\
\hline ER-negative and PR-negative & $69(54.8)$ & $329(41.5)$ \\
\hline Unknown & $4(3.2)$ & $30(3.8)$ \\
\hline \multicolumn{3}{|l|}{ Clinical stage at initial diagnosis, $n(\%)$} \\
\hline $\begin{array}{l}\text { Stage I-III, MBC } \leq 12 \text { months after } \\
\text { initial diagnosis }\end{array}$ & $23(18.3)$ & $98(12.4)$ \\
\hline $\begin{array}{l}\text { Stage I-III, MBC }>12 \text { months after } \\
\text { initial diagnosis }\end{array}$ & $64(50.8)$ & $484(61.0)$ \\
\hline Stage IV & $39(31.0)$ & $211(26.6)$ \\
\hline
\end{tabular}

${ }^{a}$ Patients could be counted in multiple CVD categories

$B M I$ body mass index, $C V D$ cardiovascular disease, $C N S$ central nervous system, ECOG Eastern Cooperative Oncology Group, ER estrogen receptor; $\max$ maximum, $M B C$ metastatic breast cancer, $\min$ minimum, $P R$ progesterone receptor

(black vs. white) on survival outcomes, while adjusting for clinically significant baseline treatment and prognostic factors. Multivariate models were adjusted for baseline

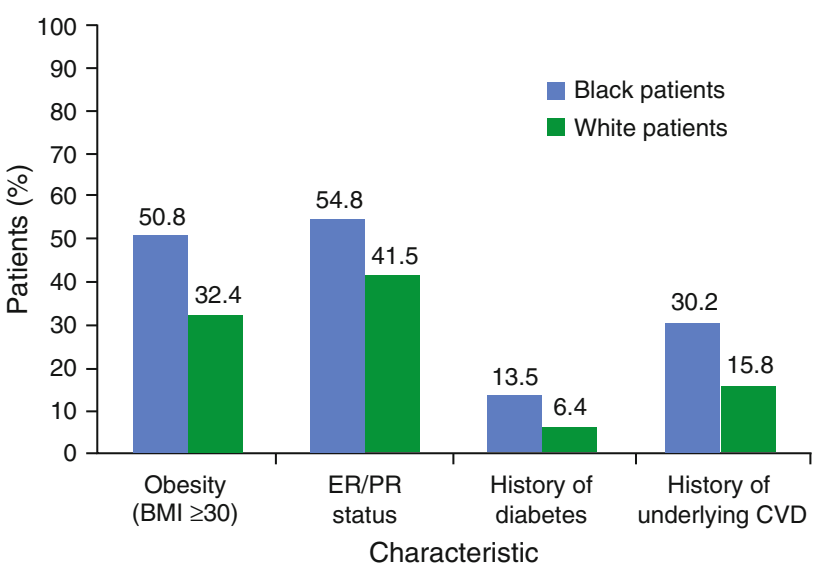

Fig. 1 Select clinical characteristics in black and white patients at the time of metastatic breast cancer diagnosis. BMI body mass index, $C V D$ cardiovascular disease, $E R$ estrogen receptor, $P R$ progesterone receptor

factors including age at enrollment, BMI, Eastern Cooperative Oncology Group (ECOG) performance status, serum albumin level, tumor ER/PR status, site of metastatic disease (adjusted using a hierarchical approach, i.e., [1] central nervous system [CNS], [2] bone only or bone plus breast, [3] visceral/other, and [4] node/local), number of metastatic sites, stage of disease at initial diagnosis, history of underlying CVD, and history of other underlying noncardiac comorbid conditions. The final multivariate models further adjusted for first-line treatment variables among patients, including receipt of trastuzumab, taxanes, and hormonal therapy. Differences in PFS and OS for black versus white patients were also investigated within subcategories of baseline and clinical characteristics, as well as treatment factors.

\section{Results}

\section{Patient characteristics}

Baseline demographics and clinical characteristics for the black and white patients who were followed until death, disenrollment, or the June 2009 data lock date are shown in Table 1. Black patients were more likely to have discontinued due to death and loss to followup compared with white patients $(62.7$ vs. $53.1 \%$ and 8.7 vs. $4.9 \%$, respectively). The median follow-up time was 21.0 months for black patients and 28.4 months for white patients. Black patients were slightly younger, had a higher prevalence of obesity (50.8 vs. $32.4 \%$ ), and had more than twice the prevalence of diabetes (13.5 vs. $6.4 \%$ ) at baseline than white patients. In addition, twice as many black patients had a history of underlying CVD at baseline than did white 
Table 2 Early-stage treatment patterns in black and white patients with recurrent disease

\begin{tabular}{lcc}
\hline Treatment, $n(\%)$ & $\begin{array}{l}\text { Black patients } \\
(n=87)\end{array}$ & $\begin{array}{l}\text { White patients } \\
(n=582)\end{array}$ \\
\hline Neoadjuvant systemic therapy & $22(25.3)$ & $118(20.3)$ \\
Adjuvant systemic therapy & $58(66.7)$ & $439(75.4)$ \\
Neoadjuvant/adjuvant trastuzumab & $6(6.9)$ & $44(7.6)$
\end{tabular}

Patients diagnosed in stages 0 -III only or with missing clinical cancer stage

Table 3 Treatment patterns for MBC prior to first disease progression among black and white patients

\begin{tabular}{lll}
\hline Treatment, $n(\%)$ & $\begin{array}{l}\text { Black } \\
\text { patients }\end{array}$ & $\begin{array}{l}\text { White } \\
\text { patients }\end{array}$ \\
\hline $\begin{array}{l}\text { Trastuzumab-based first-line } \\
\text { regimens }\end{array}$ & $(n=102)$ & $(n=670)$ \\
$\begin{array}{l}\text { With chemotherapy only } \\
\text { With hormonal therapy only }\end{array}$ & $79(77.5)$ & $438(65.4)$ \\
$\begin{array}{l}\text { With chemotherapy and } \\
\text { hormonal therapy }\end{array}$ & $5(4.9)$ & $42(6.3)$ \\
$\quad 12(11.8)$ & $138(20.6)$ \\
$\begin{array}{l}\text { Trastuzumab alone } \\
\text { Non-trastuzumab-based first-line regimens }\end{array}$ & $(n=24)$ & $(n=123)$ \\
Chemotherapy only & $9(37.5)$ & $63(51.2)$ \\
$\begin{array}{l}\text { Hormonal therapy only } \\
\text { Chemotherapy and hormonal } \\
\text { therapy }\end{array}$ & $10(41.7)$ & $44(35.8)$ \\
Untreated & $4(16.7)$ & $6(4.9)$ \\
\hline
\end{tabular}

a Those in the trastuzumab-based first-line regimens are defined as patients receiving $\geq 21$ days of trastuzumab in first-line therapy

$M B C$ metastatic breast cancer

patients (30.2 vs. $15.8 \%$ ) (see Table 1; Fig. 1). Among black patients, hypertension with complications (11.1\%) and other cardiac diseases $(20.6 \%)$ were the most commonly reported CVD conditions.

The distribution of sites of metastatic disease at diagnosis was similar for black and white patients, with visceral sites being the most common and CNS being the least common for patients of both races. More black patients than white patients, however, had an ECOG performance status of $\geq 2$ at diagnosis, had ER/PR-negative disease, and presented with de novo stage IV MBC or recurrent stage IV MBC within 12 months of initial stage I-III diagnosis (see Table 1).

Adjuvant treatment patterns in patients with recurrent disease

Treatment patterns in black and white patients with recurrent disease were similar (Table 2). Among these
Table 4 Incidence of reported cardiac adverse events (grades $\geq 3$ ) in black and white patients treated with trastuzumab

\begin{tabular}{lcc}
\hline Adverse event, $n(\%)$ & $\begin{array}{l}\text { Black patients } \\
(n=119)\end{array}$ & $\begin{array}{l}\text { White patients } \\
(n=746)\end{array}$ \\
\hline Any & $13(10.9)$ & $59(7.9)$ \\
Angina pectoris & $0(0.0)$ & $2(0.3)$ \\
Atrial arrhythmia & $1(0.8)$ & $4(0.5)$ \\
Cardiac disorder (NOS) & $2(1.7)$ & $11(1.5)$ \\
Congestive heart failure & $5(4.2)$ & $12(1.6)$ \\
Left ventricular dysfunction & $3(2.5)$ & $22(2.9)$ \\
Myocardial infarction & $2(1.7)$ & $2(0.3)$ \\
Pericardial effusion & $0(0.0)$ & $5(0.7)$ \\
Ventricular arrhythmia & $0(0.0)$ & $1(0.1)$ \\
\hline
\end{tabular}

NOS not otherwise specified

patients, the majority received adjuvant systemic therapy (66.7\% of black patients, $75.4 \%$ of white patients). Approximately $7 \%$ of both black and white patients received neoadjuvant or adjuvant trastuzumab.

Treatment patterns prior to first disease progression

Initial regimens for MBC usually included trastuzumab, and its percentage of use was comparable between black and white patients ( 81 and $84 \%$, respectively). Consistent with the observed difference in ER/PR statuses, more black patients received chemotherapy and fewer received hormonal therapy with or without chemotherapy than white patients (Table 3).

In patients who did not receive a trastuzumab-based regimen as first-line treatment, fewer black patients received chemotherapy only or were untreated, while more black patients received hormonal therapy or combined chemotherapy and hormonal therapy than white patients (see Table 3). The use of anthracycline and cumulative dose were comparable between black and white patients (data not shown).

Cardiac safety outcomes

Reported grade $\geq 3$ cardiac events in black and white patients treated with trastuzumab (in any line) are shown in Table 4 . There was a slightly higher incidence of grade $\geq 3$ cardiac events in black patients (13/119 [10.9\%]) than in white patients $(59 / 746$ [7.9\%]). The incidence of congestive heart failure was $4.2 \%(n=5)$ in black patients and $1.6 \%(n=12)$ in white patients.

When stratified by underlying disease history, black patients treated with trastuzumab and with a history of diabetes, hypertension with complications, or CVD were more likely to have cardiac safety events than white 
Fig. 2 Kaplan-Meier plots showing first-line a PFS and b OS since diagnosis of metastatic breast cancer in black and white patients. $C I$ confidence interval, $H R$ hazard ratio, $O S$ overall survival, $P F S$ progression-free survival
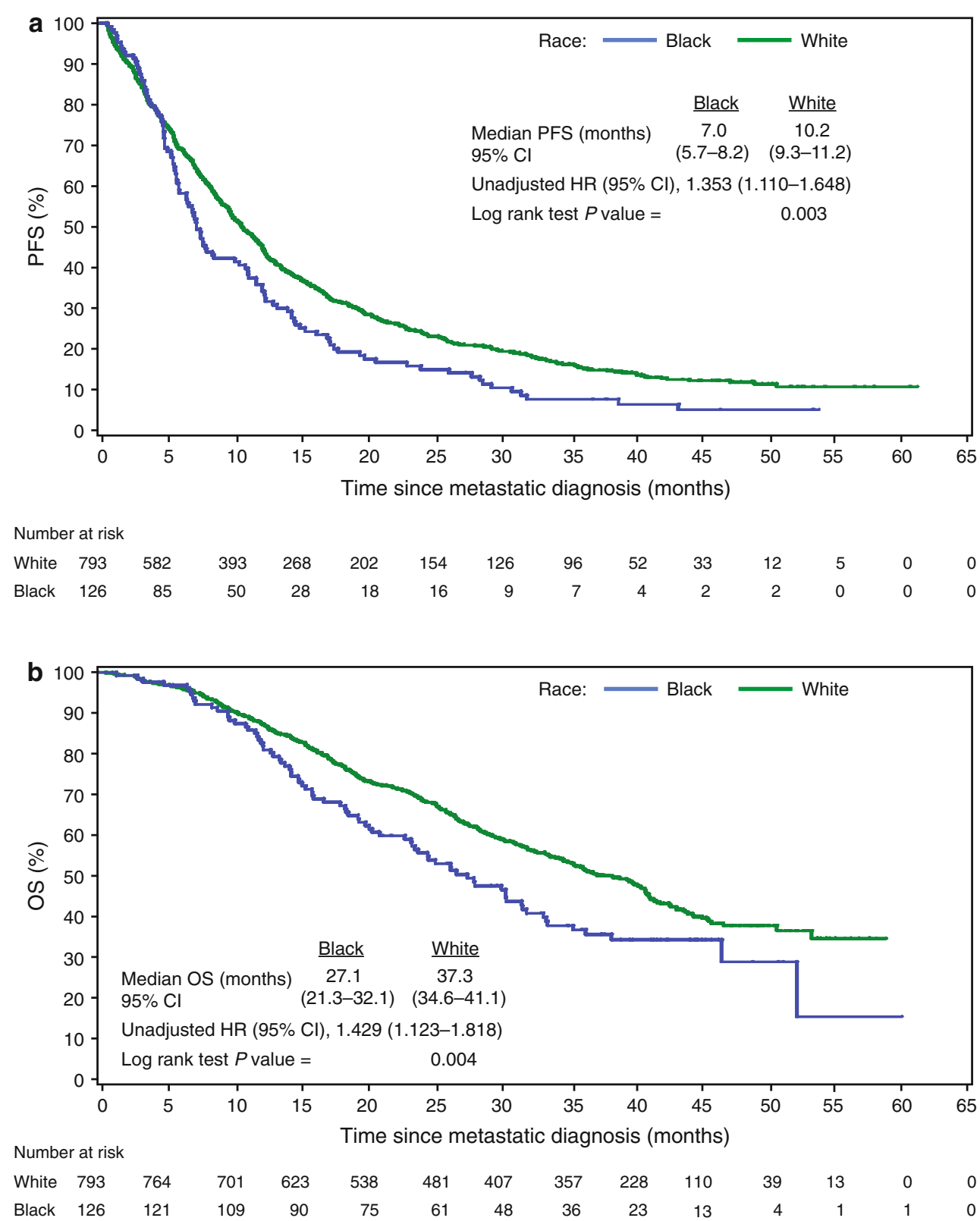

patients with the same conditions. Specifically, of the black patients who reported a history of diabetes and who had received $\geq 1$ dose of trastuzumab $(n=15)$, three $(20.0 \%)$ reported any cardiac safety event compared with four white patients $(n=48 ; 8.3 \%)$. Similarly, of the black patients who reported a history of hypertension with complications and who had received $\geq 1$ dose of trastuzumab $(n=14)$, two $(14.2 \%)$ had any cardiac safety event compared with two white patients $(n=29 ; 6.9 \%)$. A history of CVD appeared to have less of an impact; of the black patients with any history of CVD and who had received $\geq 1$ dose of trastuzumab $(n=36)$, five patients $(13.9 \%)$ had a cardiac safety event compared with 12 white patients $(n=117$; $10.3 \%)$.
Efficacy and clinical outcomes

The unadjusted median first-line PFS was substantially lower among black patients than among white patients (7.0 months [95\% CI 5.7-8.2] vs. 10.2 months [95\% CI 9.3-11.2]; Fig. 2a). Unadjusted median OS was also substantially lower among black patients than among white patients (27.1 months [95\% CI $21.3-32.1] \quad$ vs. 37.3 months [95 \% CI 34.6-41.1]; Fig. 2b).

To determine whether race had an effect on survival independent of baseline prognostic and treatment factors, we conducted a multivariate analysis controlling for baseline demographics, treatment patterns, and clinical characteristics. After adjusting for these factors, black patients 
Fig. 3 Analysis of progressionfree survival (PFS) by baseline characteristics and treatment patterns in black and white patients. $B M I$ body mass index, $C I$ confidence interval, $C N S$ central nervous system, $C V D$ cardiovascular, $E R$ estrogen receptor, $H R$ hazard ratio, met metastases, $P R$ progesterone receptor

\begin{tabular}{|c|c|}
\hline Variable & Category \\
\hline \multirow[t]{3}{*}{ ER/PR status } & Positive \\
\hline & Negative \\
\hline & Unknown \\
\hline \multirow[t]{3}{*}{ BMI category } & $<25$ \\
\hline & 25 to $<30$ \\
\hline & $\geq 30$ \\
\hline \multirow[t]{2}{*}{ CVD history } & No \\
\hline & Yes \\
\hline \multirow[t]{2}{*}{ Other disease history } & No \\
\hline & Yes \\
\hline \multirow[t]{5}{*}{ Metastatic site } & Any CNS \\
\hline & ne and/or breast \\
\hline & Visceral \\
\hline & Node/local \\
\hline & Other sites \\
\hline \multirow[t]{3}{*}{ Stage at initial diagnos } & IV \\
\hline & , met $\leq 12$ months \\
\hline & met $>12$ months \\
\hline \multirow[t]{2}{*}{$\begin{array}{l}\text { First-line } \\
\text { trastuzumab therapy }\end{array}$} & No \\
\hline & Yes \\
\hline \multirow[t]{2}{*}{$\begin{array}{l}\text { Adjuvant trastuzumab } \\
\text { therapy }\end{array}$} & No \\
\hline & Yes \\
\hline \multirow[t]{2}{*}{$\begin{array}{l}\text { Taxanes as } \\
\text { metastatic treatment }\end{array}$} & No \\
\hline & Yes \\
\hline \multirow[t]{2}{*}{$\begin{array}{l}\text { Anthracyclines as } \\
\text { metastatic treatment }\end{array}$} & No \\
\hline & Yes \\
\hline
\end{tabular}

had a significantly greater risk for disease progression compared with white patients (adjusted HR, 1.29; $95 \%$ CI $1.05-1.59 ; P=0.015)$, as well as a significantly greater risk of death (adjusted HR, 1.29; $95 \%$ CI 1.00-1.65; $P=0.049$ ).

In PFS and OS analyses within subcategories of baseline and clinical characteristics (ER/PR status, BMI category, history of CVD, other disease history, metastatic site, and stage at initial diagnosis), as well as treatment patterns (first-line trastuzumab or adjuvant trastuzumab; taxanes or anthracyclines for metastatic disease), the median PFS and OS consistently favored white patients (Figs. 3, 4). There was a trend toward poorer PFS and OS in black patients compared with white patients for both ER/PR-positive and ER/PR-negative statuses.

Among patients with disease progression after first-line therapy for advanced disease, rates of metastasis to node/

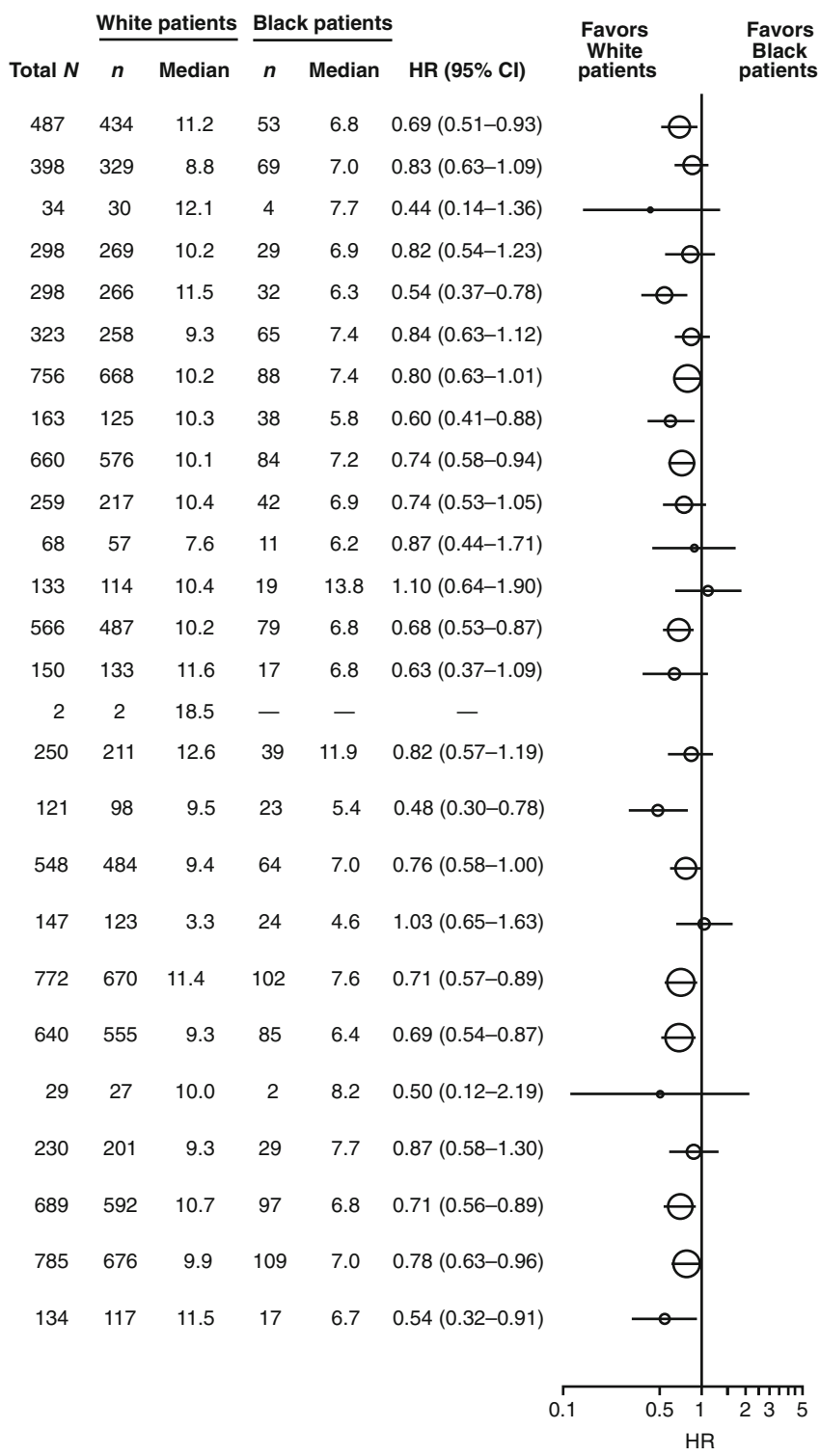

local sites were nearly twice as high in black patients $(22.2$ vs. $13.0 \%$ ) as in white patients, while rates of metastases to bone only or bone plus breast were approximately twice as high in white patients as in black patients (21.1 vs. $10.2 \%$, respectively). Black and white patients had similar rates of metastases to CNS sites (18.5 vs. $20.8 \%$ ), visceral sites (47.2 vs. $43.9 \%$ ), and other sites (1.9 vs. $1.1 \%)$, respectively.

\section{Discussion}

In this national registry study conducted in a real-world setting of patients with HER2-positive MBC, black patients were found to have more adverse prognostic factors compared with white patients, including the greater BMI and a higher proportion of ER/PR-negative tumors. These 
Fig. 4 Analysis of overall survival (OS) by baseline characteristics and treatment patterns in black and white patients. $B M I$ body mass index, $C I$ confidence interval, $C N S$ central nervous system, $C V D$ cardiovascular, $E R$ estrogen receptor, $H R$ hazard ratio, met metastases, $P R$ progesterone receptor

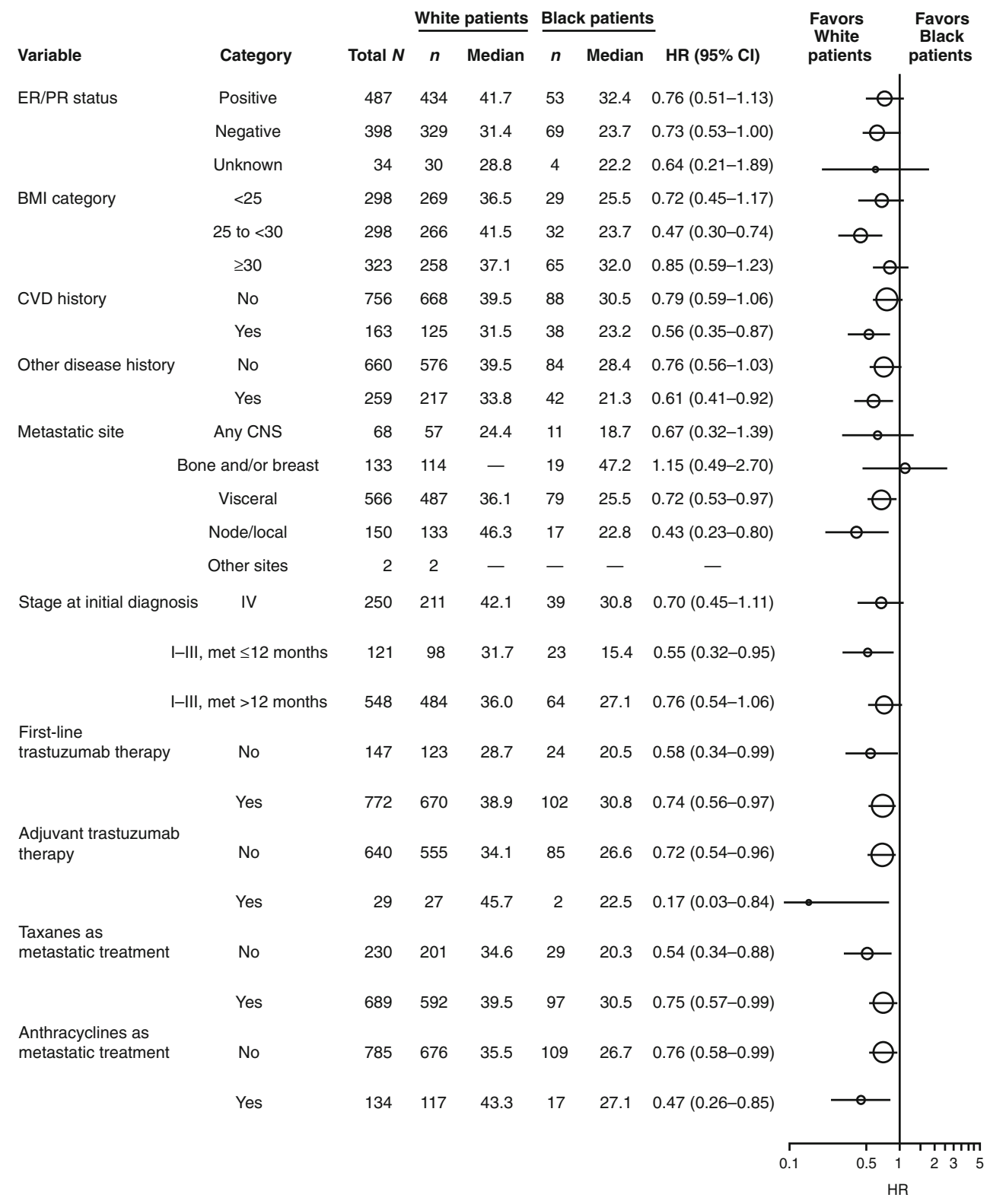

prognoses [15]. Obesity and diabetes share similar biological mechanisms for their associations with breast cancer. In addition, in line with current population-based, epidemiologic data $[16,17]$, black patients in this study had a higher rate of underlying CVD at baseline compared with white patients and were more likely to present with de novo stage IV MBC or recurrent stage IV MBC within 12 months of initial stage I-III diagnosis. However, black patients consistently demonstrated poorer outcomes, even after adjusting for differences in BMI, the prevalence of underlying CVD between black and white patients, and stage at initial diagnosis.

The unexplained poorer outcomes in black patients with HER2-positive MBC, despite controlling for prognostic factors, suggest that other influences, in particular those aggressive biological characteristics and have poor 
underlying tumor and host biology, may play a role in the etiology and health outcomes of patients with HER2positive breast cancer. One illustration of this can be observed in patients with tumors that are hormone receptor-negative, which are associated with poorer prognosis compared with hormone receptor-positive tumors [18]. Consistent with the findings in registHER, data from the large, population-based Surveillance, Epidemiology, and End Results (SEER) database have shown that African American breast cancer patients are more likely to have ER/PR-negative tumors than European American [19] and non-Hispanic white breast cancer patients [20].

Interestingly, while black patients in the registHER cohort of HER2-positive patients were more likely to have ER/PR-negative disease compared with white patients, there was a trend toward worse outcomes in black patients within both the ER/PR-positive and ER/PR-negative subsets. While the literature on this finding is limited, an earlystage analysis from a recent, large, randomized trial population treated with anthracycline- and taxane-containing chemotherapy found that racial differences in outcome were observed primarily in the ER-positive group but not in the ER-negative or HER2-positive groups [21].

There is evidence demonstrating that there are racial/ ethnic differences in breast cancer molecular subtypes in addition to HER2-positive disease, as well as gene alterations, which have been associated with breast cancer outcomes. TNBC, which is associated with poor prognosis, an aggressive and early pattern of metastases, and limited therapeutic options [22], occurs at a higher rate in indigenous African women [3], as well as in African American women $[2,4,23,24]$, compared with white women. In a recently completed sequence analysis of 434 breast cancers in Nigerian patients, high frequencies of BRCAl and $B R C A 2$ mutations were found $(7.1$ and $3.9 \%$, respectively), and 16 different BRCAl mutations were detected [25]. Alterations in p53 were significantly more common in African American women than in white women (odds ratio, $4.00 ; 95 \%$ CI 1.77-9.01) in a study of 247 tumor samples, even after adjustment for disease stage at diagnosis and other prognostic factors [26]. In 141 tumor tissue samples analyzed from 72 African American and 69 Latina women with breast cancer, more than $70 \%$ of the patients with HER2-positive disease had elevated Akt levels, a level higher than reported for other ethnic groups in most studies [27].

Given the increased prevalence of poor prognosis molecular subtypes and genetic alterations in black women with breast cancer, and the unexplained unfavorable outcomes in black patients in registHER, the current hypothesis-generating descriptive study suggests that expanded research into the role of the biology of HER2-positive MBC across race/ethnicity may provide an improved understanding of the etiology of these observations and could identify possible new targets for therapy.

To determine if racial disparities were evident for trastuzumab-associated cardiac safety events in registHER, reported cardiac safety events were compared in white and black patients treated with trastuzumab. Because the number of events in the analysis was small, results should be interpreted with caution. The incidence of cardiac safety events (collected via predefined checkboxes and physician subjective opinion) was slightly greater in black patients than white patients (10.9 vs. $7.9 \%$, respectively), as was the incidence of congestive heart failure (4.2 vs. $1.6 \%$, respectively). The contributing factors to this modest difference are unknown, but they are likely to include a higher incidence of hypertension that requires treatment in black vs. white patients, as it is known to be a risk factor for trastuzumab-induced cardiac toxicity [28]. Additional research is needed to investigate risk factors for cardiac toxicity by race among patients receiving trastuzumab.

The fact that socioeconomic data were not collected in registHER, and therefore data could not be adjusted for socioeconomic status in this analysis, is a weakness of the study. Socioeconomic factors like account for some proportion of breast cancer outcome disparities, but a majority of pooled and population-based studies show a persistence of survival differences in black patients and white patients after adjustment for socioeconomic factors [7, 29]. Interestingly, despite the observed increase in breast cancer mortality in African American breast cancer patients, these patients are more likely to experience delays in completion of adjuvant chemotherapy, are more likely to receive potentially inappropriate and substandard healthcare, are less likely to undergo preventive cancer screening, and are less likely to participate in clinical trials $[7,30]$.

In addition to the lack of socioeconomic data in registHER, an inherent limitation of this study is possible "confounding by indication" because of the nonrandomized, observational nature of the registHER study. The analysis may also include possible residual confounding due to the inability to control for prior treatments, treatment compliance, tumor size, menopausal status, and New York Heart Association Functional Classification. CVD and cardiovascular safety data were collected via predefined checkboxes and physicians subjective opinion rather than via validated methods. Also, the overall findings should be interpreted with caution due to the small number of events. Limited information was collected for cause of death (options included only "cancer" and "other") and was missing for $32 / 538$ deaths ( $>5 \%$ of deaths) in the registHER cohort $(n=1,001)$, which precluded the calculation of breast cancer-specific mortality rates in this study. 


\section{Conclusions}

These real-world data from the US-based registHER study show consistently poorer outcomes in black patients with HER2-positive MBC compared with white patients with the same disease, outcomes which were not explained by the higher prevalence of high-risk prognostic factors among black patients. These findings suggest a need to better understand possible underlying biological differences that could have a predictive or prognostic significance for black patients with HER2-positive MBC. Further prospective research is now ongoing through a second disease-based registry, SystHERs, which includes the collection of archival tumor and germline DNA to better understand not only the biology of resistance but also racial and other host differences, treatment patterns, and outcomes for patients with HER2-positive MBC.

Acknowledgments The authors thank Shibao Feng for early contributions to the analyses and Lee Bennett and Yun Wu of RTI-Health Solutions for statistical programming. Support for third-party writing assistance for this manuscript was provided by Genentech, Inc. This work was sponsored by Genentech, Inc.

Conflict of interest PAK and AMB have received consulting fees from Genentech. MUY has served on an advisory board for Roche/ Genentech. HSR and PAK have received research funding for their institutions from Genentech. BY and OOA are full-time employees of Genentech and own Roche stock. DT serves in an uncompensated capacity on a Steering Committee for a registry study funded by Genentech/Roche. MM and DAY have no disclosures.

Ethical standards These experiments comply with the current laws of the country in which they were performed.

Open Access This article is distributed under the terms of the Creative Commons Attribution Noncommercial License which permits any noncommercial use, distribution, and reproduction in any medium, provided the original author(s) and the source are credited.

\section{References}

1. Bickell NA, Wang JJ, Oluwole S, Schrag D, Godfrey H, Hiotis K, Mendez J, Guth AA (2006) Missed opportunities: racial disparities in adjuvant breast cancer treatment. J Clin Oncol 24:1357-1362

2. Carey LA, Perou CM, Livasy CA, Dressler LG, Cowan D, Conway K, Karaca G, Troester MA, Tse CK, Edmiston S, Deming SL, Geradts J, Cheang MC, Nielsen TO, Moorman PG, Earp HS, Millikan RC (2006) Race, breast cancer subtypes, and survival in the Carolina Breast Cancer Study. JAMA 295:2492-2502

3. Huo D, Ikpatt F, Khramtsov A, Dangou JM, Nanda R, Dignam J, Zhang B, Grushko T, Zhang C, Oluwasola O, Malaka D, Malami S, Odetunde A, Adeoye AO, Iyare F, Falusi A, Perou CM, Olopade OI (2009) Population differences in breast cancer: survey in indigenous African women reveals over-representation of triplenegative breast cancer. J Clin Oncol 27:4515-4521

4. Stead LA, Lash TL, Sobieraj JE, Chi DD, Westrup JL, Charlot M, Blanchard RA, Lee JC, King TC, Rosenberg CL (2009) Triple- negative breast cancers are increased in black women regardless of age or body mass index. Breast Cancer Res 11:R18

5. Tian N, Goovaerts P, Zhan FB, Wilson JG (2010) Identification of racial disparities in breast cancer mortality: does scale matter? Int $\mathrm{J}$ Health Geogr 9:35

6. Stark A, Kapke A, Schultz D, Brown R, Linden M, Raju U (2008) Advanced stages and poorly differentiated grade are associated with an increased risk of HER2/neu positive breast carcinoma only in white women: findings from a prospective cohort study of African-American and white-American women. Breast Cancer Res Treat 107:405-414

7. Newman LA (2005) Breast cancer in African-American women. Oncologist 10:1-14

8. Kwan ML, Kushi LH, Weltzien E, Maring B, Kutner SE, Fulton RS, Lee MM, Ambrosone CB, Caan BJ (2009) Epidemiology of breast cancer subtypes in two prospective cohort studies of breast cancer survivors. Breast Cancer Res 11:R31

9. Olopade OI, Fackenthal JD, Dunston G, Tainsky MA, Collins F, Whitfield-Broome C (2003) Breast cancer genetics in African Americans. Cancer 97:236-245

10. Slamon DJ, Clark GM, Wong SG, Levin WJ, Ullrich A, McGuire WL (1987) Human breast cancer: correlation of relapse and survival with amplification of the HER-2/neu oncogene. Science 235:177-182

11. Kallioniemi O-P, Holli K, Visakorpi V, Koivula T, Helin HH, Isola JJ (1991) Association of C-erbB-2 protein over-expression with high rate of cell proliferation, increased risk of visceral metastasis and poor long-term survival in breast cancer. Int $\mathbf{J}$ Cancer 49:650-655

12. Estevez L, Seidman A (2003) HER2-positive breast cancer: incidence, prognosis, and treatment options. Am J Cancer 2:169-179

13. Brufsky AM, Mayer M, Rugo HS, Kaufman PA, Tan-Chiu E, Tripathy D, Tudor IC, Wang LI, Brammer MG, Shing M, Yood MU, Yardley DA (2011) Central nervous system metastases in patients with HER2-positive metastatic breast cancer: incidence, treatment, and survival in patients from registHER. Clin Cancer Res 17:4834-4843

14. National Cancer Institute (2006) Common terminology criteria for adverse events v3.0 (CTCAE). http://ctep.cancer.gov/ protocolDevelopment/electronic_applications/docs/ctcaev3.pdf. Accessed 28 March 2013

15. Vona-Davis L, Rose DP (2012) Type 2 diabetes and obesity metabolic interactions: common factors for breast cancer risk and novel approaches to prevention and therapy. Curr Diabetes Rev 8:116-130

16. Jolly S, Vittinghoff E, Chattopadhyay A, Bibbins-Domingo K (2010) Higher cardiovascular disease prevalence and mortality among younger blacks compared to whites. Am J Med 123:811-818

17. Banegas MP, Li C (2012) Breast cancer characteristics and outcomes among Hispanic black and Hispanic white women. Breast Cancer Res Treat 134:1297-1304

18. Amend K, Hicks D, Ambrosone CB (2006) Breast cancer in African-American women: differences in tumor biology from European-American women. Cancer Res 66:8327-8330

19. Joslyn SA (2002) Hormone receptors in breast cancer: racial differences in distribution and survival. Breast Cancer Res Treat 73:45-59

20. Ooi SL, Martinez ME, Li CI (2011) Disparities in breast cancer characteristics and outcomes by race/ethnicity. Breast Cancer Res Treat 127:729-738

21. Sparano JA, Wang M, Zhao F, Stearns V, Martino S, Ligibel JA, Perez EA, Saphner T, Wolff AC, Sledge GW Jr, Wood WC, Davidson NE (2012) Race and hormone receptor-positive breast cancer outcomes in a randomized chemotherapy trial. J Natl Cancer Inst 104:406-414 
22. Anders CK, Deal AM, Miller CR, Khorram C, Meng H, Burrows E, Livasy C, Fritchie K, Ewend MG, Perou CM, Carey LA (2011) The prognostic contribution of clinical breast cancer subtype, age, and race among patients with breast cancer brain metastases. Cancer 117:1602-1611

23. Ihemelandu CU, Leffall LD Jr, Dewitty RL, Naab TJ, Mezghebe HM, Makambi KH, Adams-Campbell L, Frederick WA (2007) Molecular breast cancer subtypes in premenopausal and postmenopausal African-American women: age-specific prevalence and survival. J Surg Res 143:109-118

24. Lund MJ, Trivers KF, Porter PL, Coates RJ, Leyland-Jones B, Brawley OW, Flagg EW, O'Regan RM, Gabram SG, Eley JW (2009) Race and triple negative threats to breast cancer survival: a population-based study in Atlanta, GA. Breast Cancer Res Treat 113:357-370

25. Fackenthal JD, Zhang J, Zhang B, Zheng Y, Hagos F, Burrill DR, Niu Q, Huo D, Sveen WE, Ogundiran T, Adebamowo C, Odetunde A, Falusi AG, Olopade OI (2012) High prevalence of BRCA1 and BRCA2 mutations in unselected Nigerian breast cancer patients. Int J Cancer 131:1114-1123

26. Jones BA, Kasl SV, Howe CL, Lachman M, Dubrow R, Curnen MM, Soler-Vila H, Beeghly A, Duan F, Owens P (2004) African-
American/White differences in breast carcinoma: p53 alterations and other tumor characteristics. Cancer 101:1293-1301

27. Wu Y, Mohamed H, Chillar R, Ali I, Clayton S, Slamon D, Vadgama JV (2008) Clinical significance of Akt and HER2/neu overexpression in African-American and Latina women with breast cancer. Breast Cancer Res 10:R3

28. Tan-Chiu E, Yothers G, Romond E, Geyer CE Jr, Ewer M, Keefe D, Shannon RP, Swain SM, Brown A, Fehrenbacher L, Vogel VG, Seay TE, Rastogi P, Mamounas EP, Wolmark N, Bryant J (2005) Assessment of cardiac dysfunction in a randomized trial comparing doxorubicin and cyclophosphamide followed by paclitaxel, with or without trastuzumab as adjuvant therapy in node-positive, human epidermal growth factor receptor 2-overexpressing breast cancer: NSABP B-31. J Clin Oncol 23:7811-7819

29. Du XL, Lin CC, Johnson NJ, Altekruse S (2011) Effects of individual-level socioeconomic factors on racial disparities in cancer treatment and survival: findings from the National Longitudinal Mortality Study, 1979-2003. Cancer 117:3242-3251

30. Abidoye O, Ferguson MK, Salgia F (2007) Lung carcinoma in African Americans. Nature 4:118-129 